\title{
Prediction of critical times for water-extracted avocado oil heated at high temperatures
}

\author{
Brice Ulrich SAHA FOUDJO ${ }^{1,2 *}$, Germain $\mathrm{KANSCI}^{2}$, Elie $\mathrm{FOKOU}^{2}$ and Claude $\mathrm{GENOT}^{3}$ \\ ${ }^{1}$ School of Health and Medical Sciences, Catholic University of Cameroon, \\ PO Box 782 Bamenda, Cameroon. \\ ${ }^{2}$ Department of Biochemistry, University of Yaoundé I, PO Box 812 Yaoundé, Cameroon. \\ ${ }^{3}$ UR1268 BIA (Biopolymères Interactions Assemblages), INRA, F-44316 Nantes, France. \\ *Corresponding author; E-mail: sahabrice@yahoo.fr; Tel: +237 699262269.
}

\section{ACKNOWLEDGEMENTS}

This research project was funded by the Bayer Science \& Education Foundation through the Otto Bayer Scholarship, Germany. We are also grateful for the support of the Hohenheim University, Germany; National Research Institute of Agriculture and Development (IRAD), Foumbot Station, Cameroon.

\begin{abstract}
Vegetable oils are used in various cooking processes. However, when they are heated at high temperature and/or for a long period, chemical reactions can generate damaging substances for the health. The aim of the study was to predict the critical times at high temperatures of avocado oil. A four-level two-variable Central Composite Design was used to model the thermal oxidation of avocado oil extracted using the aqueous method. Temperature $\left(120-180{ }^{\circ} \mathrm{C}\right)$ and time $(11-209 \mathrm{~min})$ were the independent variables. The response variable was the content in total polar compounds (TPC) with an upper limit defined at $25 \%$ (w/w). The composition and the oxidative status of fresh avocado oil were also investigated. The results obtained by a multiple regression analysis showed that data can be fitted with a second order polynomial equation $\left(\mathrm{R}^{2}=0.98\right.$, Adj. $\left.\mathrm{R}^{2}=0.97\right)$ with all regression coefficients being significant $(\mathrm{p}<0.05)$. The critical heating time ranged from $232 \mathrm{~min}$ to $214 \mathrm{~min}$ between $120{ }^{\circ} \mathrm{C}-140{ }^{\circ} \mathrm{C}$ and from $188 \mathrm{~min}$ to $4 \mathrm{~min}$ between $140{ }^{\circ} \mathrm{C}-180{ }^{\circ} \mathrm{C}$. It was influenced by avocado oil composition. Thus, water-extracted avocado oil is not recommended for frying $\left(140{ }^{\circ} \mathrm{C}-180^{\circ} \mathrm{C}\right)$ while it can be used for recipes involving long cooking time at moderate temperature $\left(120^{\circ} \mathrm{C}-140{ }^{\circ} \mathrm{C}\right)$.

(C) 2018 International Formulae Group. All rights reserved.
\end{abstract}

Keywords: Avocado oil, heat treatment, polar compounds, Central Composite Design, upper limit heating time.

\section{INTRODUCTION}

Oil, an important plant material, has become an integral part of human diet. One major drawback in their handling and utilization is linked to their richness in unsaturated fatty acids making them prone to oxidative deteriorations especially during thermal treatment. Oxidation renders the oils less acceptable to consumers or for industrial 
use as food ingredients (Angaye and Maluelosi, 2015).

Edible oils used as cooking medium at high temperatures are subject to thermooxidation, polymerization, and hydrolysis. The results are undesirable off-flavors and a decrease of the nutritional quality of the fried products (Nzikou et al., 2009). The stability of oils at elevated temperature depends on their fatty acid composition, their contents in natural antioxidants (tocopherols, phenolic compounds, sterols and carotenoids), and the presence of oxygen (Gordon and Magos, 1983; Kamal-Eldin and Appelqvist, 1996; Manzi et al., 1998; Choe and Min, 2006). Other components such as chlorophyll have prooxidant properties (Gutierrez-Rosales et al., 1992). Hence, proper control of processing conditions is required to delay the time when edible oils become useless (Shankar, 2014).

Many methods (peroxide value, conjugated dienes, para-anisidine value and TBARS value) are commonly used to monitor oxidation of foods (Abuzaytoun and Shahidi, 2006). But the quality indicator currently used in frying process is the content in total polar compounds (TPC). Directives establish its highest value in oils at $25 \%$ (Roman, 2012). TPC can thus be used to set up operating conditions that avoid the formation at high temperatures of inacceptable amounts of toxic compounds.

Avocado (Persia americana) oil is relatively new for culinary applications. Its production which has been developing in the early twenty-first century now reaches approximately 2000 tons/year that is a relatively small amount compared to other oils. In fact, only limited information is readily available on this product (Woolf et al., 2008). As avocado oil has not been considered as an important source of oil, few studies concern its properties for culinary application (Berasategi et al., 2012). Avocado oil possesses a similar fatty acid profile as olive oil. It contains around $76 \%$ monounsaturated fatty acids (oleic acid), 12\% polyunsaturated fatty acids (linoleic and linolenic acids) and $12 \%$ saturated fats (palmitic and stearic acids). Avocado oil is rich in antioxidants, with $\alpha$ - tocopherol (70-190 mg/kg of oil) representing the main antioxidant and to a lesser extent $\beta$-, $\gamma$ - and $\delta$-tocopherols. Carotenoids range between 1 - $3.5 \mathrm{mg} / \mathrm{kg}$ oil. Pulp-extracted avocado oil contains also chlorophyll between 11 - $19 \mathrm{mg} / \mathrm{kg}$ oil (Wong et al., 2010). Woolf et al. (2008) estimated the phytosterol content of avocado oil between $3.3-4.5 \mathrm{mg} / \mathrm{g}$ oil.

Mathematical modeling is an effective way of representing a particular process. It can help us to explore and understand the relationship between the process parameters and the quality of the products characterized by specific indicators. It can help to understand the quantitative behavior of a system (Shankar, 2014). To our knowledge, few studies are based on the modelling of edible oil oxidation at high temperatures (Ojanguren and Ayo, 2013; Shankar, 2014). Guillen and Uriarte (2011) have predicted the time at which linseed, sunflower, extra-virgin olive, grapeseed, soybean, sesame, rapeseed, peanut and hazelnut oils submitted to high temperature reached the limit of safety. The authors used the threshold value of TPC versus time and temperature, in a single-factor experimental design.

Nowadays, Response Surface Methodology (RSM) has gradually attracted the attention of many researchers. The method allows a reduction of the number of experiments and an understanding of the pattern in which the measured response is affected by changes in factors (Nuran, 2007). Its main advantage is that it allows the improvement of products from predicted properties thanks to prediction of interactive effects and effects due to collective contributions to the measured response. The most widely used RSM model is the Central Composite Rotatable Design (Alhassan et al., 2014).

This study aimed firstly at predicting critical oxidation times of crude avocado oil at high temperatures using a central composite design. The chemical properties of waterextracted avocado oil along with its oxidative status were also determined. 


\section{MATERIALS AND METHODS \\ Plant material}

The cultivar Lula of Persia americana was provided by the National Research Institute of Agriculture and Development (IRAD), Foumbot Station, Cameroon. Aqueous extraction was conducted as described by Saha Foudjo et al. (2012). The operating conditions were: time (180 min), $\mathrm{pH}$ (4.5), temperature $\left(45^{\circ} \mathrm{C}\right)$ and water/pulp ratio (6).

\section{Determination of avocado oil composition Chlorophyll content}

Chlorophyll content was determined as described in IUPAC (1995). The absorbance of $0.1 \mathrm{~g}$ of avocado oil per $\mathrm{ml}$ of hexane was measured at $630 \mathrm{~nm}, 670 \mathrm{~nm}$ and $710 \mathrm{~nm}$. The chlorophyll content was then calculated using the absorption coefficient of pheophytin $a$ $\left(345.3 \mathrm{M}^{-1} \cdot \mathrm{cm}^{-1}\right)$. It was expressed in $\mathrm{g} \mathrm{Eq}$ pheophytin $a$ per $100 \mathrm{~g}$ of oil.

\section{Carotenoid content}

Carotenoid content was determined as described by Ong et al. (1982). The absorbance of $6 \mathrm{mg}$ of avocado oil per $\mathrm{ml}$ of iso-octane was measured at $446 \mathrm{~nm}$. Carotenoid content was determined using the absorption coefficient of $\beta$-carotene $\left(2610 \mathrm{M}^{-}\right.$ $\left.{ }^{1} . \mathrm{cm}^{-1}\right)$ and expressed in $\mathrm{g} \mathrm{Eq} \beta$-carotene per $100 \mathrm{~g}$ of oil.

\section{Tocopherol composition}

The method was conducted according to Buttris and Diplock (1984) with the procedure described in Kabri et al. (2013). The avocado oil dissolved in $n$-hexane was analyzed using a HPLC (Ultimate@RS300, Dionex, France) coupled to a fluorescence detector (RF2000, Dionex, France). A silica column (Dionex advantage polar 2, $250 \mathrm{~mm} x$ $3 \mathrm{~mm}$ ID) maintained at $30^{\circ} \mathrm{C}$ was used. The signal was recorded at an excitation of $290 \mathrm{~nm}$ and an emission of $330 \mathrm{~nm}$. Standard curves of tocopherols $(\alpha, \beta, \gamma, \delta)$ were drawn for their quantification in avocado oil. The results were expressed as $\mathrm{g} / 100 \mathrm{~g}$ of oil.

\section{Squalene content and sterol composition}

The procedure was conducted according to ISO 12228 (1999). 5 $\alpha$-cholestane was used as internal standard. After saponification, the sterols and squalene were analyzed using a gas chromatograph (Perkin Elmer Autosystem XL, Germany) equipped with a capillary column DB-5 (30 m of length, $0.32 \mathrm{~mm}$ ID, and $0.25 \mu \mathrm{m}$ of thickness) and an ionization detector. The external standards were composed of: squalene $(0.02 \mathrm{mg} / \mathrm{ml})$, $5 \alpha$-cholestane $(0.02 \mathrm{mg} / \mathrm{ml})$, brassicasterol $(0.014 \mathrm{mg} / \mathrm{ml}), \delta 5$-campesterol $(0.012 \mathrm{mg} / \mathrm{ml})$, stigmasterol $(0.013 \mathrm{mg} / \mathrm{mL})$ and $\beta$-sitosterol $(0.019 \mathrm{mg} / \mathrm{ml})$. The results were expressed in $\mathrm{g} / 100 \mathrm{~g}$ of oil.

\section{Fatty acid composition}

The procedure was conducted according to AOCS (1989). A volume of 0.5 $\mathrm{ml}$ of pentadecanoic acid $0.5 \mathrm{mg} / \mathrm{ml}$ was used as internal standard. After alkaline methylation with $\mathrm{BF}_{3}(13-15 \%)$ at $100{ }^{\circ} \mathrm{C}$ for $5 \mathrm{~min}$, the fatty acids were analyzed using a gas chromatograph (Perkin Elmer Auto system XL, Germany). The methylated forms of the following fatty acids were used as external standards at $0.5 \mathrm{mg} / \mathrm{mg}$ : myristic acid, pentadecanoic acid, palmitic acid, palmitoleic acid, stearic acid, oleic acid, linoleic acid and linolenic acid. The results were expressed in $\mathrm{g} / 100 \mathrm{~g}$ of oil and as percentages of total quantified fatty acids.

\section{Determination of the oxidative status of avocado oil Peroxide value}

Peroxide value was determined as described by Jian et al. (1992). $15.5 \mathrm{mg}$ of avocado oil were dissolved with $9.9 \mathrm{ml}$ chloroform/methanol 7:3 (v/v), $50 \mu 1$ xylenol orange $10 \mathrm{mM}$ and $50 \mu \mathrm{l}$ iron (II) chloride $0.5 \%$. After $5 \mathrm{~min}$, the produced iron (III) complexed with xylenol orange to form a chromophore that absorbs at $560 \mathrm{~nm}$. The absorbance was measured at $560 \mathrm{~nm}$ against a blank. A calibration curve of cumene hydroperoxide was used to determine the peroxide value expressed in $\mathrm{mEq}$ oxygen $/ \mathrm{kg}$ oil.

\section{Conjugated diene content}

Conjugated dienes content were determined as described by IUPAC (1987). The absorbance of $0.8 \mathrm{mg}$ of avocado oil dissolved in $1 \mathrm{ml}$ of isooctane was measured 
at $233 \mathrm{~nm}$. The absorption coefficient of the hydroperoxide of linoleic acid: $2.52510^{4} \mathrm{M}^{-}$ ${ }^{1} . \mathrm{cm}^{-1}$ was used. Conjugated dienes were expressed as $\mu \mathrm{mol} / \mathrm{g}$ of oil.

\section{Para-anisidine value}

Para-anisidine value was determined as described by ISO 6885 (2006 modified). The absorbance of a tube containing $0.25 \mathrm{~g}$ of avocado oil in $5 \mathrm{ml}$ of isooctane and $1 \mathrm{ml}$ of para-anisidine was measured at $350 \mathrm{~nm}$ against a blank after keeping it in a dark place for $8 \mathrm{~min}$.

\section{Malonadialdehyde determination}

The procedure was conducted as described by Viau et al. (2016). After extraction and complexation with thiobarbituric acid (TBA), malonadialdehyde (MDA) was detected and quantified as MDATBA adduct with an UHPLC system (Dionex RS-LC Ultimate 3000) paired with an UV-vis detector. Signal acquisition was made at the wavelength of $535 \mathrm{~nm}$. The data were expressed as MDA content in nmol/g oil with a calibration curve of MDA.

\section{Total polar compound determination}

Total polar compound content (TPC) was determined as described by Dobarganes et al. (2000). A chromatography column (10 $\mathrm{mm} \times 150 \mathrm{~mm}$ ) containing $5 \mathrm{~g}$ of silica gel 60 (Merck Millipore, Germany) was used to fractionate $0.5 \mathrm{~g}$ of avocado oil dissolved in 5 $\mathrm{ml}$ petroleum ether/diethyl ether 90:10 $(\mathrm{v} / \mathrm{v})$.The non-polar fraction was first eluted with $60 \mathrm{ml}$ petroleum ether/diethyl ether 90:10 (v/v) and then the polar fraction with 50 $\mathrm{ml}$ diethyl ether. After evaporation, the 2 fractions were weighed. The TPC content was expressed as $\mathrm{g} / 100 \mathrm{~g}$ of oil.

\section{Heating process}

For each experiment, $600 \mathrm{mg}$ of avocado oil were heated in a beaker on a temperature-controlled magnetic stirrer. Temperature and duration of thermal treatment were determined by the modelling design calculation (table 1). After heating, each avocado oil sample was cooled down and its content $(\% \mathrm{w} / \mathrm{w})$ in total polar compounds (TPC) determined.

\section{Modelling Design}

The study area defined for the independent variables: heating temperature and time (Table 1), was applied to a four-level two-variable Central Composite Design (CCD) (Myers and Montgomery, 2002). The TPC content was chosen as the response variable and the value of $25 \%$ was fixed as the upper limit to reduce health risks linked to the ingestion of thermally-oxidized oils. The independent variables were coded according to the following formula:

$$
x_{i}=\frac{X_{i}-X_{0}}{\Delta X_{i}}, \quad i=1,2,
$$

where $x_{\mathrm{i}}$ is the dimensionless coded value of $X_{i}, X_{\mathrm{o}}$ the value of $X_{\mathrm{i}}$ at the central point, and $\Delta X_{i}$ the step.

Sixteen experiments were randomly run. The following general second order polynomial equation was used to depict the thermal stability of water-extracted avocado oil:

$$
\mathbf{Y}=\beta \mathrm{o}+\Sigma \beta_{\mathrm{i}} \boldsymbol{x}_{i}+\Sigma \beta_{i i} x_{i}^{2}+\Sigma \beta_{i j} x_{i} x_{j}+\varepsilon
$$

where $\mathrm{Y}$ is the response variable (TPC content in \%); $\beta_{\mathrm{o}}, \beta_{\mathrm{i}}, \beta_{\mathrm{ij}}$ and $\beta_{\mathrm{ii}}$ are the constant coefficients of the intercept, linear, quadratic and interaction terms respectively; $x_{\mathrm{i}}$ and $x_{\mathrm{j}}$ are coded independent variables and $\varepsilon$ represents the residue.

\section{Statistical analysis}

The lack-of-fit test, ANOVA, DurbinWatson test, significance of the regression coefficients and the coefficients of determination $\left(\mathrm{R}^{2}\right.$ and $\left.\mathrm{Adj} . \mathrm{R}^{2}\right)$ were calculated to assess the robustness and suitability of the fitted second-order polynomial equation. The significance level was $\mathrm{p}<0.05$. The regression analysis was conducted with the software Statgraphics Plus 5.1 . 
Table 1: Coded values and levels of independent variables used in the Central Composite Design used to model the effect of heat treatments on water-extracted avocado oil.

\begin{tabular}{lcc}
\hline \multirow{2}{*}{ Coded values } & \multicolumn{2}{c}{ Independent variables } \\
\cline { 2 - 3 } & Temperature $\left({ }^{\circ} \mathbf{C}\right)$ & Time $(\mathbf{m i n})$ \\
\hline-1.41 & 120 & 11 \\
-1 & 130 & 40 \\
0 & 155 & 110 \\
+1 & 180 & 180 \\
+1.41 & 190 & 209 \\
\hline
\end{tabular}

\section{RESULTS \\ Composition of avocado oil}

The avocado oil used in this study contained monounsaturated fatty acids, $69 \%$ of the total quantified fatty acids, $3 \%$ polyunsaturated fatty acids and $28 \%$ saturated fatty acids (Table 2). It also contained phytosterols, vitamin E, chlorophyll, carotenoids and squalene (Table 2). Among the 4 forms of tocopherols identified, the $\alpha$ form was the main component (92.6\%) and $\delta$ form had the lowest amount $(0.1 \pm 0.0 \mu \mathrm{g} / \mathrm{g}$ oil). No tocotrienols were detected. From the 4 forms of phytosterol identified, $\beta$-sitosterol was the most abundant (82.9\%) and stigmasterol the less represented $(20 \pm 4$ $\mathrm{mg} / 100 \mathrm{~g}$ oil).

\section{Oxidative status of freshly-extracted avocado oil}

The results of the assessment of the oxidative status of avocado oil before heating process can be found in table 3 . The results suggested that very small amounts of primary oxidative products (dienes and hydroperoxides) and secondary oxidative products (MDA) were generated during the extraction process. The polar compounds represented $8 \pm 4 \%$ of the oil.

\section{Modeling of polar compounds formation and prediction of critical heating times of water-extracted avocado oil}

The TPC content of water-extracted avocado oil submitted to heat treatment according to the 16 experiments of the Central Composite Design (CCD) varied between $10 \%$ and $60 \%$. The lowest TPC content was observed for a heating time of $11 \mathrm{~min}$ and a temperature of $155^{\circ} \mathrm{C}$. The highest TPC was obtained after $180 \mathrm{~min}$ at $180^{\circ} \mathrm{C}$. To test if CCD could describe the relationship between polar compounds formation and both temperature and time, the lack-of-fit test was calculated. The lack-of-fit test was not significant $(p=0.05)$, which demonstrates that the multiple regression equation properly explained the relationship between the formation of polar compounds and both temperature and time (Table 3). The coefficient of determination, $\mathrm{R}^{2}(0.98)$, very close to 1 , denoted a high correlation between observed and predicted values. The coefficient of determination was almost similar to the adjusted $R^{2}(0.97)$ showing that the model accurately described the relationship that binds the TPC content to the factors temperature and time. The curvature observed in the response surface and contour plots was due to the quadratic terms of temperature and time (Figure 1). The shape of the response surface plot confirmed the suitability of a second order model. The set of points of the homoscedasticity of residues (Figure 2) was distributed almost uniformly around the horizontal axis, which indicates that the residual variance was constant. The DurbinWatson test was not significant $(\mathrm{t}=2.36, \mathrm{p}=$ 0.34 ), the residues were therefore not correlated. In sum, the hypotheses formulated on the residuals for a linear regression model were respected. The analysis of variance (Table 3) showed that all regression terms were highly significant $(\mathrm{p}<0.01)$. The following polynomial second order equation was derived:

$$
\begin{gathered}
\text { TPC }=14.60+8.49 x_{1}+14.77 x_{2}+ \\
3.86 x^{2}{ }_{1}+10.05 x^{2}{ }_{2}+6.22 x_{1} x_{2}
\end{gathered}
$$


Where $x_{1}$ and $x_{2}$ are respectively the coded values of time and temperature. TPC is the total polar compound content (\%).

According to the parameters of the above equation and the response surface plot, the total polar compound content during heating of avocado oil increases when either temperature and/or time increases. Based on the equation coefficients, temperature has a higher effect than time during thermal oxidation $(14.77>8.49)$. Figure 1 showed that the total polar compound content was nearly constant between $120-140{ }^{\circ} \mathrm{C}$. Indeed, according to the well-known effect of temperature on chemical reactions and as currently observed for thermos-oxidation of edible oil, an increase of the temperature used for cooking $\left(>140{ }^{\circ} \mathrm{C}\right)$ adversely affected the oxidative stability of avocado oil. When the heating temperature did not exceed $140{ }^{\circ} \mathrm{C}$, TPC were formed at very slow rates and their level remained low and under the limit (25\%) even after a heating time longer than $3 \mathrm{~h} 30 \mathrm{~min}$. When temperature was higher than $140{ }^{\circ} \mathrm{C}$, TPC increased sharply with heating time.

The results shown in table 4 evidenced that the upper limit for heating time decreased as the temperature increased. It remained fairly constant between $120^{\circ} \mathrm{C}$ to $140{ }^{\circ} \mathrm{C}$. This is in agreement with the graph analysis done above (Figure 1).

Table 2: Chemical composition of the freshly-extracted avocado oil.

\begin{tabular}{|c|c|c|c|c|}
\hline \multicolumn{5}{|c|}{ SAPONIFIABLE MATTER } \\
\hline Classes & Fatty acids & $\begin{array}{c}\text { Contents } \\
\left(10^{-2} \mathrm{~g} / 100 \mathrm{~g}\right)\end{array}$ & $\begin{array}{c}\text { Percentages } \\
(\%)\end{array}$ & $\begin{array}{c}\text { Total } \\
(\%)\end{array}$ \\
\hline \multirow{3}{*}{ Saturated fatty acids } & myristic acid & $2 \pm 0$ & $0 \pm 0$ & \multirow{3}{*}{$28 \pm 1$} \\
\hline & palmitic acid & $2280 \pm 32$ & $26 \pm 1$ & \\
\hline & stearic acid & $168 \pm 7$ & $2 \pm 0$ & \\
\hline \multirow{4}{*}{$\begin{array}{l}\text { monounsaturated } \\
\text { fatty acids } \\
\text { polyunsaturated fatty } \\
\text { acids }\end{array}$} & palmitoleic acid & $2277 \pm 21$ & $25 \pm 1$ & \multirow[b]{2}{*}{$69 \pm 0$} \\
\hline & oleic acid & $3967 \pm 158$ & $44 \pm 1$ & \\
\hline & linoleic acid & $185 \pm 7$ & $2 \pm 0$ & \multirow{2}{*}{$3 \pm 0$} \\
\hline & linolenic acid & $74 \pm 3$ & $1 \pm 0$ & \\
\hline \multicolumn{2}{|l|}{ Total } & 9039 & 100 & 100 \\
\hline \multicolumn{5}{|c|}{ UNSAPONIFIABLE MATTER } \\
\hline \multicolumn{2}{|l|}{ Constituents } & Sub-constituents & \multicolumn{2}{|c|}{ Content } \\
\hline \multicolumn{2}{|c|}{ Chlorophyll $\left(10^{-4} \mathrm{~g} / 100 \mathrm{~g}\right.$ oil $)$} & & \multicolumn{2}{|c|}{$9 \pm 2$} \\
\hline \multicolumn{2}{|c|}{ Carotenoid $\left(10^{-4} \mathrm{~g} / 100 \mathrm{~g}\right.$ oil $)$} & & \multicolumn{2}{|c|}{$4 \pm 0$} \\
\hline \multicolumn{2}{|c|}{ Squalene $\left(10^{-3} \mathrm{~g} / 100 \mathrm{~g}\right.$ oil $)$} & & \multicolumn{2}{|c|}{$133 \pm 7$} \\
\hline \multirow{4}{*}{\multicolumn{2}{|c|}{ Tocopherols $\left(10^{-5} \mathrm{~g} / 100 \mathrm{~g}\right.$ oil $)$}} & $\alpha$ & \multicolumn{2}{|c|}{$263 \pm 1$} \\
\hline & & $\beta$ & \multicolumn{2}{|c|}{$3 \pm 0$} \\
\hline & & $\gamma$ & \multicolumn{2}{|c|}{$17 \pm 0$} \\
\hline & & $\delta$ & \multicolumn{2}{|c|}{$1 \pm 0$} \\
\hline \multirow{4}{*}{\multicolumn{2}{|c|}{ Sterols $\left(10^{-3} \mathrm{~g} / 100 \mathrm{~g}\right.$ oil $)$}} & Brassicasterol & \multicolumn{2}{|c|}{$22 \pm 9$} \\
\hline & & $\Delta 5$-campesterol & \multicolumn{2}{|c|}{$63 \pm 2$} \\
\hline & & stigmasterol & \multicolumn{2}{|c|}{$20 \pm 4$} \\
\hline & & $\beta$-sitosterol & \multicolumn{2}{|c|}{$506 \pm 39$} \\
\hline
\end{tabular}


Table 3: Indicators of oxidation status of the freshly-extracted avocado oil.

\begin{tabular}{lc}
\hline Parameters & Content \\
\hline Peroxide value (meq oxygen/kg) & $4 \pm 0$ \\
Para-anisidine value & $4 \pm 2$ \\
MDA content $(\mathrm{nmol} / \mathrm{g})$ & $3 \pm 0$ \\
Conjugated diene content $(\mu \mathrm{mol} / \mathrm{g})$ & $3 \pm 0$ \\
Total polar compound content $(\%)$ & $8 \pm 4$ \\
\hline
\end{tabular}

Table 4: Significativity of parameters and adequation of the Central Composite Design during heat treatments of water-extracted avocado oil.

\begin{tabular}{lccccc}
\hline Parameter & $\begin{array}{c}\text { Sum of } \\
\text { squares }\end{array}$ & $\begin{array}{c}\text { Degree of } \\
\text { freedom }\end{array}$ & $\begin{array}{c}\text { Mean } \\
\text { squares }\end{array}$ & F-ratio & p-value \\
\hline$\beta_{1}$ & 577.21 & 1 & 577.21 & 209.89 & $0.0000^{*}$ \\
$\beta_{2}$ & 1744.97 & 1 & 1744.97 & 634.53 & $0.0000^{*}$ \\
$\beta_{11}$ & 119.27 & 1 & 119.27 & 43.37 & $0.0000^{*}$ \\
$\beta_{22}$ & 809.11 & 1 & 809.11 & 56.390 & $0.0000^{*}$ \\
$\beta_{12}$ & 155.03 & 1 & 155.03 & 294.22 & $0.0000^{*}$ \\
Lack-of-fit test & 35.58 & 3 & 11.86 & 4.31 & 0.0500 \\
Pure error & 19.24 & 7 & 2.75 & & \\
\hline
\end{tabular}

* Significant level $(\mathrm{p}<0,05)$; F-ratio: ratio of Fisher.

Table 5: Predicted upper limit heating times $\left(t_{25 \%}\right)$ of water-extracted avocado oil at different temperatures with a upper limit for total polar compound content defined at $25 \%$.

Temperature $\left({ }^{\circ} \mathbf{C}\right)$

Predicted upper limit heating time at $25 \%$ (min)

\begin{tabular}{ll}
\hline 120 & 232 \\
130 & 230 \\
140 & 214 \\
150 & 188 \\
160 & 151 \\
170 & 97 \\
180 & 4 \\
\hline
\end{tabular}




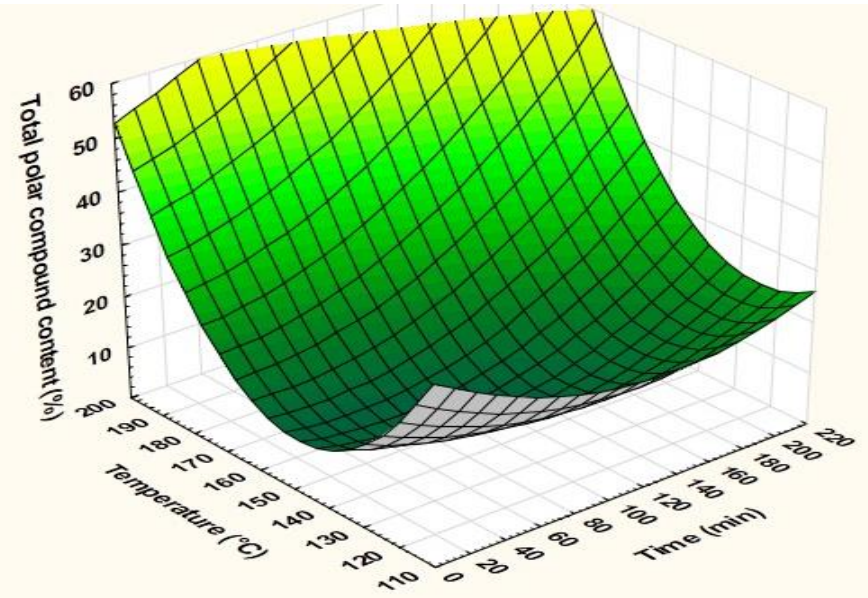

A

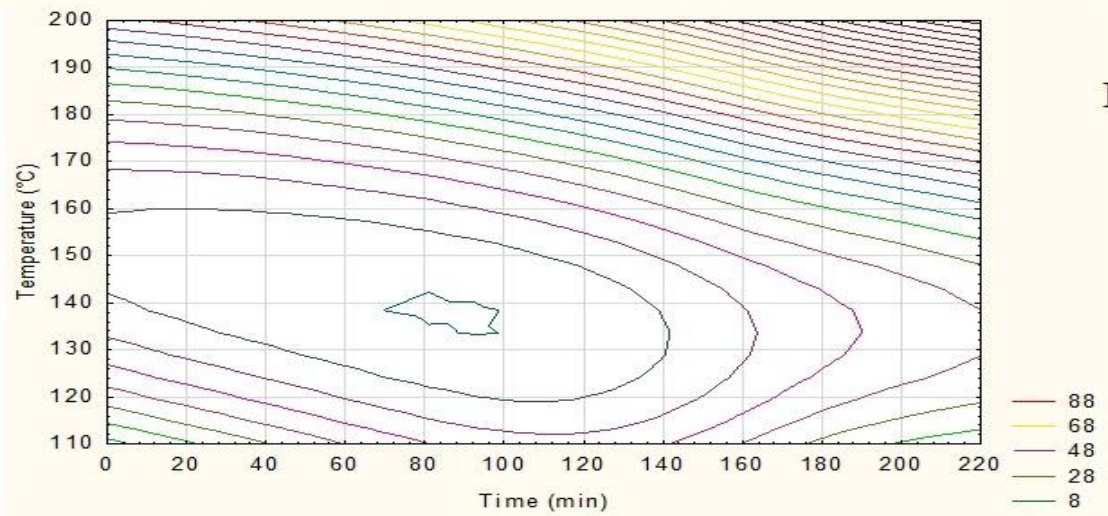

Figure 1: Plots showing the effect of temperature and time on the total polar compounds content of water-extracted avocado oil after heat treatments: (A) response plot and (B) contour plot.

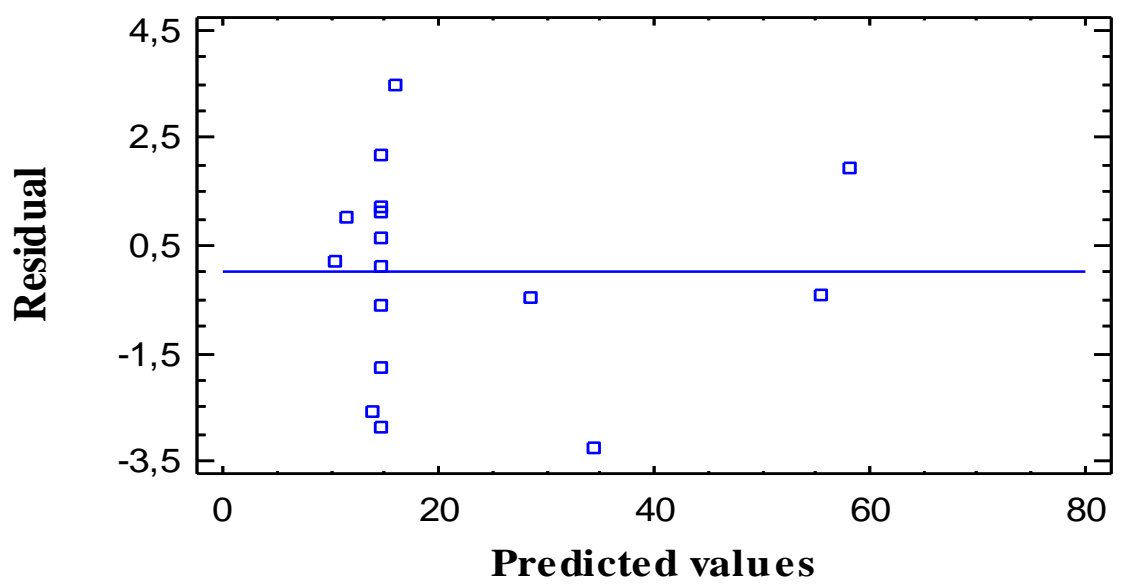

Figure 2: Homoscedasticity of residues for the modeling of avocado oil oxidation. 


\section{DISCUSSION}

The oxidative status of the oil after extraction, namely the presence of oxidationderived compounds, can affect the rate of the oxidation (Min et Jung, 1989). The peroxide value was well below the admissible value for an edible oil of good quality that is $20 \mathrm{meq}$ oxygen $/ \mathrm{kg}$ (O'Connor et al., 2007). Content of conjugated dienes content was in the same order that the value recommended for virgin olive oil in the Codex Alimentarius (2001) that is $3.5 \mu \mathrm{mol} / \mathrm{g}$. MDA content was lower than that of olive oil $(2 \mathrm{mmol} / \mathrm{g})$, reported by Romojaro et al. (2013). MDA content was also found to be lower compared to fresh rapeseed, sunflower, kiwiseed and tuna oils $(0.6$ to $29 \mu \mathrm{mol} / \mathrm{kg})$ reported by Viau et al. (2016). Para-anisidine value (4.5) was also below the recommended values, 20 (arbitrary unit), by GOED for omega-3 oils (GOED, 2012). The very low level of oxidative indicators suggest that the $8 \%$ of the TPC did not come from oxidative products but from polar lipids naturally present in crude unrefined vegetable oils such as free fatty acids and membrane lipids (phospho- and glycolipids), slightly polar (amphiphilic) lipids such as monoacylglycerols, diacylglycerols (Dulf et al., 2013) and other polar compounds such as phenolics. Thus, the avocado oil produced with the aqueous extraction method was of good quality based on the oxidative indicators.

Time and temperature are prominent but controllable influencing factors on thermo-oxidation of edible oils. For instance, time was also found as a key factor in the prediction of limit frying time of sunflower oil (Farhoost and Tavassoli-Hafrani, 2011). These authors observed a linear relationship between total polar compound content and time in agreement with Guillén and Uriarte (2011) working on 17 edible oils among them virgin olive oil, sunflower and linseed oils. Guillén and Uriarte (2011) also observed that the more the oil is rich in oleic acid the less it produces polar compounds while the reverse was found for oils rich in linoleic and linolenic acids. Two-third of fatty acids of the avocado oil used for this study was monounsaturated fatty acids. Thus, based on its fatty acid profile it was only moderately susceptible to oxidation. Additionally, it contained appreciable amounts of natural antioxidants such as tocopherols, carotenoids and sterols.

The limit heating time, for which a TPC content of the avocado oil was predicted to reach $25 \%$, was found to decrease from about 3 hours to 4 min when the temperature increased from $150{ }^{\circ} \mathrm{C}$ to $180{ }^{\circ} \mathrm{C}$. Beresategi et al. (2012) showed that cold-pressed avocado oil and virgin olive oil had the same thermal stability at $180{ }^{\circ} \mathrm{C}$. These authors reported a lower phytosterol content (339.6 $\mathrm{mg} / 100 \mathrm{~g}$ ) and a higher content of tocopherols (245 $\mu \mathrm{g} / \mathrm{g}$ ) compared to that of this study. Phytosterols might inhibit the polymerization process during oxidation (Gordon and Magos, 1983). Tocopherols (284 $\left.10^{-5} \mathrm{~g} / 100 \mathrm{~g}\right)$ compete with unsaturated fatty acids for peroxyl radicals and are converted to tocopheroxyl radicals, more stable that their lipid analogues and inhibit the propagation of oxidation (Kamal-Eldin and Appelavist, 1996). Tocopherols can be regenerated by squalene $(0.1 \mathrm{~g} / 100 \mathrm{~g})$ (Manzi et al., 1998). Moreover, carotenoids present in avocado oil $\left(410^{-4} \mathrm{~g} / 100 \mathrm{~g}\right)$ play an antioxidant role by scavenging singlet oxygen and radicals and inactivating sensitizers (Chloe and Min, 2006). In contrast, chlorophyll $\left(910^{-4} \mathrm{~g} / 100 \mathrm{~g}\right.$ oil) and its derivatives present in the oil are known to act as sensitizers to promote oxidation (Gutierrez-Rosales et al., 1992).

\section{Conclusion}

The results presented in this study showed that avocado oil produced with aqueous extraction method contained antioxidant and prooxidant compounds. Moreover, the freshly-produced avocado oil was of good quality based on the oxidative indicators. The four-level two-variable Central Composite Design was suitable and robust enough to predict each upper limit heating time of avocado oil at high temperatures. For the temperature range chosen $\left(120^{\circ} \mathrm{C}-\right.$ 
$180^{\circ} \mathrm{C}$ ), the upper limit heating time varies between $232 \mathrm{~min}$ to $4 \mathrm{~min}$. TPC content evolved in 2 phases between $120^{\circ} \mathrm{C}-180{ }^{\circ} \mathrm{C}$ : a rapid increase between $140{ }^{\circ} \mathrm{C}-180^{\circ} \mathrm{C}$ and a stationary phase between $120^{\circ} \mathrm{C}-140{ }^{\circ} \mathrm{C}$. Thus, water-extracted avocado oil is not recommended for cooking at high temperatures $\left(140{ }^{\circ} \mathrm{C}-180{ }^{\circ} \mathrm{C}\right)$ such as frying while it can be used for recipes involving long cooking time at moderate temperature $\left(120^{\circ} \mathrm{C}-140{ }^{\circ} \mathrm{C}\right)$.

\section{COMPETING INTERESTS}

The authors declare that they have no competing interests.

\section{AUTHORS' CONTRIBUTIONS}

BUSF collected the sample, performed experiments and wrote the manuscript. GK, $\mathrm{EF}$ and CG supervised the experiments and revised critically for important intellectual content. All authors read and approved the final manuscript.

\section{ACKNOWLEDGEMENTS}

We are thankful to Lucie Ribourg, from Biopolymères Interactions Assemblages Research Unit (French National Institute for Agricultural Research), who performed analysis of tocopherols and malondialdehydes.

\section{REFERENCES}

Abuzaytouna R, Shahidi F. 2006. Oxidative Stability of Flax and Hemp Oils. J. Am. Oil Chem. Soc., 83(10): 855-861. DOI: 10.1007/s11746-006-5037-7.

Alhassan Y, Kumar N, Bugaje IM, Mishra C. 2014. Optimization of Gossypium arboreum seed oil biodiesel production by central composite rotatable model of response surface methodology and evaluation of its fuel properties. J. Pet. Technol. Altern. Fuels, 5(1): 1-12. DOI: 10.5897/JPTAF2013.0093.

Angaye SS, Maduelosi NJ. 2015. Comparative Study of the Physicochemical Properties of Some Refined Vegetable Oils Sold in Mile One Market and Some Departmental Stores in
Port Harcourt, Rivers State, Nigeria. Discourse J. Agric. Food Sci., 3(5): 7882.

AOCS. 1989. Methods Ce 1b-89 and Ce 2-66. In Official Methods and Recommended Practices of the American Oil Chemists'Society, $\quad\left(4^{\text {th }} \quad\right.$ edn $)$ Mehlenbacher VC, Hopper TH, Sallee EM, Link WE, Walker RO, Walker RC, Firestone D (Eds). AOCS: Champlain, III.

Berasategi I, Barriuso B, Ansorena D, Astiasarán I. 2012. Stability of avocado oil during heating: Comparative study to olive oil. Food Chem., 132: 439-446. DOI: https://doi.org/10.1016/j.foodchem. 2011.11.018.

Buttris JL, Diplock AT. 1984. Highperformance liquid chromatography methods for vitamin E in tissues. Method Enzymol., 105: 131-138. DOI: https://doi.org/10.1016/S0076-6879 (84)05018-7.

Choe E, Min DB. 2006. Mechanisms and Factors for Edible Oil Oxidation: Comprehensive Reviews. Comp. Comp. Rev. Food Sci. Food Safety, 5: 169 185.

DOI: https://doi.org/10.1111/j.1541-4337. 2006.00009.

Codex Alimentarius. 2001. Fats, Oils and Related Products ( $2^{\text {nd }}$ edn). FAO and OMS: Rome.

Dobarganes MC, Velasco J, Dieffenbacher A. 2000. Determination of polar compounds, polymerized and oxidized triacylglycerols and diacylglycerols in oils and fats. J. Pure Appl. Chem., 72: 1563-1575.

DOI: https://doi.org/10.1351/pac20007208156 3.

Dulf FV, Oroian I, Vodnar DC, Socaciu C, Pintea A. 2013. Lipid classes and fatty acid regiodistribution in triacylglycerols of seed oils of two Sambucus species $(S$. nigra L. and S. ebulus L.). Molecules, 18: $\quad 11768-11782 . \quad$ DOI: 10.3390/molecules181011768. 
Farhoosh R, Tavassoli-Kafrani MH. 2011. Simultaneous monitoring of the conventional qualitative indicators during frying of sunflower oil. Food Chem., 125: 209-213. DOI: 10.1016/j.foodchem.2010.08.064.

GOED. 2012. The GOED voluntary monograph quality standard for EPA and DHA oils. GOED http://www. goedomega3.com/index.php/ourmembers/quality-standards.

Gordon MH, Magos P. 1983. The effect of sterols on the oxidation of edible oils. Food Chem., 10: 141-147. DOI: https://doi.org/10.1016/0308-8146 (83)90030-4.

Guillén MD, Uriarte PS. 2011. A very simple, fast, and non-destructive approach to predict the time at which edible oils submitted to high temperature reach the established limits of safety. Food Chem., 127: 802-806. DOI:10.1016/j.foodchem. 2010.12.154.

Gutierrez-Rosales F, Garrido-Femandez J, Gallardo-Guerrero L, Gandul-Rojas B, Minguez- Mosquera MI. 1992. Action of chlorophylls and the stability of virgin olive oil. J. Am. Oil Chem. Soc., 69: 866-871. DOI: 10.1007/BF02636334.

ISO 12228 (International Organisation for Standardization 12228). 1999. Determination of Individual and Total Sterols Contents - Gas Chromatographic Method: Animal and Vegetable Fats and Oils (Part 1). International Organisation for Standardization: Genève.

IUPAC (International Union of Pure and Applied Chemistry). 1995. Determination of chlorophyll pigments in crude vegetable oils. Pure \& Appl. Chem., 67(10): 1781-1787.

IUPAC (International Union of Pure and Applied Chemistry). Method 2.505. 1987. Evidence of purity and deterioration from ultraviolet spectrophotometry. In Standard Methods for the Analysis of Oils, Fats and Derivatives $\left(7^{\text {th }}\right.$ edn) Paquot C,
Hautfenne A (eds). Blackwell Scientific: Palo Alto, Calif; 212-213.

Jiang ZY, Hunt JV, Wolf SP. 1992. Ferrous ion oxidation in the presence of xylenol orange for detection of lipid hydroperoxide in low density lipoprotein. Anal. Biochem., 202: $384-$ 389 . DOI: $10.1016 / 0003-$ 2697(92)90122-N.

Kabri T, Meynier A, Bontemps D, Gaillard C, Foucat L, Linder M, Genot C. 2013. Formulation of sub-micron emulsions containing docosahexaenoic acid esterified in triacylglycerols or phospholipids. Eur. J. Lipid Sci. Technol., 115: 1294-1308. DOI: https://doi.org/10.1002/ejlt.201300045.

Kamal-Eldin A, Appelqvist LA. 1996. The chemistry and antioxidant properties of tocopherols and tocotrienols. Lipids, 31: 671-701. DOI: https://doi.org/10.1007/ BF02522884.

Manzi P, Panfili G, Esti M, Pizzoferrato L. 1998. Natural antioxidants in the unsaponifiable fraction of virgin olive oils from different cultivars. J. Sci. Food Agr., 77: 115-120. DOI: https://doi.org/10.1002/ (SICI) 10970010(199805)77:1<115: AIDJSFA13>3.0.CO; 2-N.

Min DB, Jung MY. 1989. Effects of minor components on the flavor stability of vegetable oils. In Flavor Chemistry of Lipid Foods, Min DB, Smouse TH, (eds). AOCS Press: Champaign, Ill; 242-264.

Myers R, Montgomery DC. 2002. Response Surface Methodology ( $2^{\text {nd }}$ edn). John Wiley and Sons: New York.

Nuran B. 2007. The Response Surface Methodology. $\mathrm{PhD}$ thesis, Indiana University, Indiana, p 54-70.

Nzikou JM, Matos L, Moussounga JE, Ndangui CB, Pambou-Tobi NP, Bandzouzi EM, Kimbonguila, A, Linder M, Desobry S. 2009. Study of oxidative and thermal stability of vegetable oils during frying. Res. J. Appl. Sci., 4: 94- 
100. DOI: http://medwelljournals.com/ abstract/?doi=rjasci.2009.94.100.

O'Connor CJ, Lal SND, Eyres L. 2007. Handbook of Australasian Edible Oils. Oils and Fats Specialist Group of NZIC : Auckland, New Zealand.

Ojanguren A, Ayo J. 2006. Mathematical modelling to predict oxidative behaviour of conjugated linoleic acid in the food processing industry. Foods, 2: 274 281. DOI: $10.3390 /$ foods 2020274.

Ong ASH, Boey PL, NG CM. 1982. Spectrophotometric method for determination of solid fat content of palm oil. J. Am. Oil Chem. Soc., 59(5): $223-226$.

Roman O. 2012. Mesure et prédiction de la réactivité des lipides au cours du chauffage d'huiles végétales à haute température. $\mathrm{PhD}$ thesis, Instituts des Sciences et Industries du Vivant et de l'Environnement, France, p. 172.

Romojaro A, Sanchez-Bel P, Serrano M, Pretel MT. 2013. Wild edible plants as potential antioxidants in vegetables oils. J. $\quad$ Chem., 4 p. $\quad$ DOI: http://dx.doi.org/10.1155/2013/457902.

Saha Foudjo BU, Kansci G, Fokou E, Lazar IM, Pontalier PY, Etoa FX. 2012. Multiresponse optimization of aqueous oil extraction from five varieties of Cameroon-grown avocados. Environ. Eng. Manag. J., 11(12): 2257-2263.
Shankar R. 2014. Mathematical Modeling of Degree of Thermal Oxidation of Edible Oil (Rape seed) as a Function of Induction Time at Fixed Induced Power During Microwave Heating. IJISR, 5(2): 10.

Viau M, Genot C, Ribourg L, Meynier A. 2016. Amounts of the reactive aldehydes, malonaldehyde, 4-hydroxy-2hexenal, and 4-hydroxy-2-nonenal in fresh and oxidized edible oils do not necessary reflect their peroxide and anisidine values. Eur. J. Lipid Sci. Technol., 118: 435-444. DOI: http://dx.doi.org/10.1002/ejlt.201500103

Werman MJ, Neeman I. 1986. Oxidative stability of avocado oil. J. Am. Oil Chem. Soc., 63(3): 355 - 360. DOI: https://doi.org/10.1007/BF02546046.

Wong M, Requejo-Jackman C, Woolf A. 2010. What is unrefined, extra virgin cold-pressed avocado oil? Inform., 21(4): 198 - 202. DOI:10.1016/j.foodres. 2010.01.013.

Woolf A, Wong M, Eyres L, McGhie T, Lund C, Olsson S, Wang Y, Bulley C, Wang M, Friel E, Requejo-Jackman C. 2008. Avocado oil. In Gourmet and HealthPromoting Specialty Oil, Moreau RA, A. Kamal-Eldin (Eds). AOCS: Urbana; 73 125. 